\title{
REVIEW JURNAL PENELITIAN KOMODIFIKASI MODEL ENDORSE DALAM INDUSTRI BUDAYA FASHION DAN KOSMETIKA
}

(Hiperrealitas Fashion Endorse pada Produk Kosmetik dan Busana Remaja di Media Sosial Instagram)

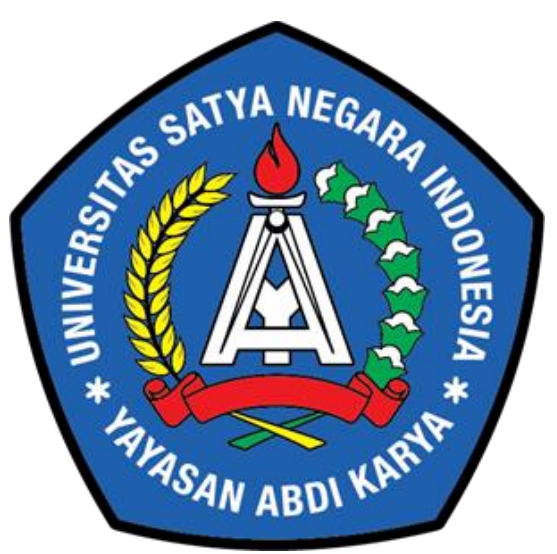

Judul : JURNAL PENELITIAN KOMODIFIKASI MODEL ENDORSE

DALAM INDUSTRI BUDAYA FASHION DAN KOSMETIKA (Hiperrealitas Fashion

Endorse pada Produk Kosmetik dan Busana Remaja di Media Sosial Instagram)

Reviewer : Firda Sardilah (180900037)

Penulis $\quad$ : Radita Gora Tayibnapis, S.Sos, M.M. dan Sandra Olifia S.Sos, M.Si.

Halaman : : 33-46

Mata kuliah : : Teori Komunikasi

FAKULTAS FISIP

JURUSAN ILMU KOMUNIKASI

UNIVERSITAS SATYA NEGARA INDONESIA

TAHUN AJARAN 2020/2021 


\section{$\underline{\text { Review }}$}

$\underline{\text { Latar Belakang }}$

Jurnal yang saya bahas yaitu merupakan jurnal yang ditulis oleh Dosen Fakultas Ilmu Sosial dan Politik Prodi Ilmu Komunikasi, Universitas Satya Negara Indonesia. Yaitu Radita Gora Tayibnapis, S.Sos, M.M. dan Sandra Olifia S.Sos, M.Si. Memulai tulisannya yang menjelaskan tentang media social yang sangat berpengaruh di kehidupan kita sekarang dan semakin banyak model endorse yang mempromosikan barang seperti fashion dan kosmetik di Instagram. Selanjutnya, mengenai latar belakang penelitian. Penelitian tersebut dilatarbelakangi oleh penggunaan media social yang semakin meningkat dan banyak sekali model endorse yang ditawarkan untuk memromosikan barang fashion atau kosmetik melalui jejaring sosila media Instagram. Banyak sekali penjual e commerce yang mempromosikan julannya di media social karena media social sangat efektif dan terus menambah penggunanya setiap harinya.

Menurut Mc Luhan "Media adalah pesan karena media membentuk dan mengendalikan skala serta bentuk hubungan dan tindakan manusia" (Bungin, 2017)

Menurut Mc Quail Media massa adalah institusi yang menghubungkan seluruh unsur masyarakat satu dengan yang lainnya dengan melalui produk media massa yang dihasilkan. Secara spesifik institusi media massa adalah sebagai saluran produksi dan distribusi konten simbolis. (Bungin, 2017). Media sosial sangat berkaitan erat di massa sekarang ini karena semua hal yang kita lakukan pasti di publish oleh media sosial. Misalnya ketika kita sedang pergi berlibur pasti kita mempublish kegiatan kita selama liburan. Maka dari itu sekarang sangat mudah untuk orang mengetahui aktivitas apa yang kita lakukan. Apalagi seperti orang yang sudah terkenal di platfrom social media pasti banyak sekali pengikut yang melihat aktivitas yang ia lakukan, dan pasti banyak sekali pengikut yang ingin mempunyai kesamaan dalam fashion yang ia gunakan. Maka dari itu endorse sangat berpengaruh untuk model atau artis-artis yang sangat aktif di media sosial. Endorse itu sama seperti iklan yang membuat orang tertarik untuk membeli kosmetik atau fashion yang digunakan oleh model atau artis tersebut. Harga endorse lebih murah dari pada memasang iklan di televisi dan endorse sangat lebih menarik perhatian kita sebagai pengguna media sosial .Endorse lebih menguntungkan untuk penjual barang-barang fashion atau kosmetik karena endorse dilakukan oleh model atau artis yang pasti memiliki wajah yang cantik atau tampan dan enak dilihat. Oleh karena itu banyak masyarakat yang tertarik untuk membeli produk tersebut. Endorse sangat 
menguntungkan untuk penjual bisnis online karena pada zaman sekarang masyarakat lebih tertarik dengan membeli produk online ketimbang offline karena dengan harga yang lebih murah dan barang langsung sampai dirumah dan pembayaran lebih efisien. Sangat memudahkan masyarakat untuk belanja online, dan sekarangpun banyak sekali aplikasi belanja online yang digunakan oleh masyarakat untuk belanja online.

Model endorse mempromosikan barang seperti kosmetik yang membuat masyarakat tertarik untuk membelinya, karena model tersebut seperti mensugesti masyarakat untuk membelinya. Walaupun banyak sekali model endorse yang tidak paham produk kosmetik yang kandungannya baik atau tidak untuk dipakai , karena model endorse kosmetik jarang benar-benar menggunakan produk kosmetik tersebut. Sangat bahaya ketika model endorse tidak mengetahui kandungan kosmetik yang ia promosikan karena pasti banyak masyarakat pengguna social media yang ingin membeli produk kecantikan wajah tersebut. Dan apabila digunakan pasti menimbulkan efek yang negatif. Maka dari itu, sangat disayangkan apabila model endorse lebih memilih uang yang ditawarkan penjual kosmetik abal-abal daripada keselamatan masyarakat pengguna media sociai. Menggunakan jasa endorsement memiliki keuntungan yang cukup tinggi karena persaingan pasar online yang menjual produk yang berbagai macam. Dari hasil endorse sebagai penjual mendapatkan keutungan yang cukup banyak, karena pasti banyak pengguna sosial media yang tersugesti untuk membeli produk tersebut. 


\section{$\underline{\text { Pembahasan }}$}

Model endorse semakin banyak berkembang sejalan dengan pesatnya pertumbuhan teknologi sosial media di era digital. Kini semakin banyak penjual yang melirik endorsement sebagai bentuk promosi agar barang atau jasa laris manis di pasaran. Apalagi promosi jenis ini bisa dibilang praktis dan efektif karena tidak butuh banyak biaya dan peraturan, namun hasilnya bisa jadi sangat berpengaruh terhadap penjualan.

Sangat praktis karena sistem endorsement tidaklah ribet. Kedua belah pihak bahkan bisa melakukan transaksi melalui pesan singkat atau bahkan melalui fitur direct messange pada media sosial. Setelah menyepakati aturan yang diberlakukan oleh artis atau selebgram, tahap selanjutnya tinggal mengirim foto atau video beserta caption yang ingin disertakan dalam postingan. Efektivitas endorsement juga bisa dibilang lebih baik jika dibandingkan dengan beberapa promosi lainnya. Terutama jika dibandingkan dengan bentuk promosi tradisional seperti flyer atau selebaran yang hampir tidak lagi dilakukan oleh pihak online shop. Ada beberapa jenis endorsement yang biasa dilakukan oleh artis atau selebgram di Indonesia. Yaitu mereka yang tidak terikat dalam sebuah produk atau brand tertentu dan mereka yang menjadi brand ambassador. Dari segi penerima endorse, keduanya memiliki keuntungan dan kelebihan masing-masing. Cara kerja endorsement di media social sebenarnya tidak jauh berbeda dengan flyer atau selebaran yang mempromosikan produk dan jasa. Hanya saja, platform yang digunakan melalui media social seperti Instagram, Facebook, Twitter, atau YouTube. Memanfaatkan dari tingginya pengguna sosial media, endorsement dinilai lebih efektif karena artinya semakin banyak juga kemungkinan orang melihat porduk yang dipromosikan.

Tujuan utama endorse adalah untuk meningkatkan penjualan sebuah produk atau jasa, sehingga terjadi peningkatan pula pada pendapatan.Manfaat melakukan iklan atau promosi melalui endorse adalah kita tidak hanya bisa mendapatkan peningkatan pendapatan. Produsen atau penjual juga akan mendapatkan manfaat lain dari endorse, seperti pengenalan produk, branding merk, hingga mendapatkan kepercayaan dari calon konsumen karena memanfaatkan nama si artis atau selebgram.Pelaku usaha yang mengiklankan produk dan jasa mereka lewat Instagram bukan hanya dari produsen besar. Pemilik online shop kecil pun dengan mudah dapat memanfaatkan endorsement untuk meningkatkan penjualan. 
Fashion dan kosmetika, bagi masyarakat modern tidak lagi dianggap sebagai pemenuhan kebutuhan sekunder, namun juga dipandang sebagai kebutuhan primer yang harus terpenuhi. Sehingga penawaran trend busana-busana baru dengan beragam variasi atau model-model yang beragam dan dari berbagai versi, memudahkan bagi para konsumen atau khalayak luas dalam memilih produk meskipun penawaran produk dan jenis busana atau kosmetik yang ditawarkan memiliki banyak jenis dan beragam. Sehingga keberadaan fashion dan produk kosmetik terus menjadi incaran bagi para khalayak luas terutama yang tersegment pada remaja di tingkat pendidikan Menengah dan pendidikan tinggi.

Masyarakat media social sekarang secara tidak sadar sudah mengalami Hiperrealitas atau Hyperealty. Hiperrealitas yaitu suatu kondisi dimana seseorang secara tidak sadar sulit membedakan kenyataan hidup dengan dunia fantasi atau dunia maya. Dalam keadaan tersebut masyarakat pengguna sosial media sekarang secara tidak sadar sudah lupa akan kehidupan nyatanya. Seperti contohnya pengguna social media lebih sering curhat atau bercerita di Twitter ataupun Facebook. Mereka berbagi ceritanya kepada orang banyak. Dari sisi itu mereka secara tidak sadar menjadi Hipperealitas dalam menggunakan media sosial.

Media berhasil membuat realitas baru yang salu mengedepankan hal yang sempurna untuk membuai manusia. Sebagai contoh adalah masalah tentang "relatif kecantikan". Media sangat realitas tentang kecantikan, bahwa kecantikan itu adalah wanita yang mempunyai kulit putih, hidung mancung, alis rapih, bulu mata cetar. Sehingga setiap wanita yang ingin tampil cantik harus memenuhi kreteria tersebut. Dan hal ini pun terjadi pada diri lelaki tersebut dimana media berhasil menciptakan realitas dimana lelaki tersebut akan mendapatkan perempuan yang ia inginkan yang tidak ia dapatkan di dunia nyata sesungguhnya. Oleh karena itu, media berhasil menciptakan tanda-tanda sebagai realitas yang baru yang lebih baik dari realitas yang sesungguhnya. Kita sebagai pengguna media sosial juga tidak sadar bahwa kebudayaan kita lama kelamaan akan terkikis oleh kebudayaan baru atau budaya populer. Dari kebiasaan kita memakai barang fashion dari luar negri, membeli barang dari luar negri, mendengarkan musik kpop, menonton film drama korea. Ketika kita melakukan semua hal itu memang secara tidak sadar kita lupa akan kebudayaan kita sendiri. 


\section{Teori yang Digunakan dalam Penelitian}

\section{Hiperrealitas dan Simulacra}

Kajian realitas pada media mencoba mengkritisi bagaimana konten media tidak selalu bersinggungan antara yang nyata dengan tidak nyata. Sherry Turkle melukiskan tentang realitas virtual sebagai berikut: realitas virtual memberikan gambaran terhadap kehidupan yang lebih nyata dibandingkan kehidupan nyata itu sendiri". Dalam artian yang nyata lenyap karena longsoran simulasi dan yang muncul adalah realitas yang mengatasi realitas real, realitas yang lebih cantik dari yang cantik, lebih benar dari yang benar. (Gora \& Olifia, 2019)

Penciptaan realitas tersebut menggunakan satu model produksi yang oleh Baudrillard Menurut Piliang disebutnya dengan simulasi, yaitu penciptaan model-model nyata yang tanpa asal usul atau realitas awal. Hal ini olehnya disebut (hiper-reality). Melalui model simulasi, manusia dijebak di dalam satu ruang, yang didasarinya sebagai nyata, meskupun sesungguhnya semu, maya, atau khayalan belaka. (Gora \& Olifia, 2019)

Menurut Nugroho Ruang realitas semu itu merupakan satu ruang antithesis dari representasi, atau seperti apa yang dikatakan oleh Derrida antithesis itu dapat disebut dengan dekonstruksi terhadap representasi realitas itu sendiri (Gora \& Olifia, 2019)

Semiotik berhubungan dengan hubungan antara tanda, penandaan, dan pikiran manusia. Tradisi ini sangat berpengaruh dalam membantu kita melihat bagaimana tanda dan simbol digunakan, apa maknanya dan bagaimana mengaturnya. Penelitian yang melihat pada pengaturan simbol dalam sebuah pesan didasarkan pada pemikiran semiotik. Pesan-pesan media sangat menarik dari sudut pandang semiotik karena pesan-pesan tersebut biasanya terdiri atas campuran simbol-simbol yang diatur secara spsial dan kronologis untuk menciptakan sebuah kesan, menyampaikan sebuah gagasan, atau memunculkan sebuah pemaknaan audiens. Semiotik telah memberikan alat bantu yang kuat untuk menguji pengaruh media massa. Sebagian besar setuju bahwa tanda-tanda memiliki kepentingan khusus dalam media, dan media membentuk, pada tingkatan yang lebih tinggi, bagaimana tanda berfungsi bagi kita. Sebagai sebuah contoh teori semiotik tentang media, kita akan melihat pada karya Jea Baudrillard, yang percaya bahwa media telah memberikan jarak antara simbol dan pengalaman dunia yang sebenarnya. (Littlejohn, Stephen W dan Foss, 2018) 
Budaya komoditas kita yang didorong oleh media merupakan salah satu aspek simulasi tempat kita hidup. Lingkungan tiruan memberi tahu kita apa yang harus dilakukan, lingkungan ini membentuk selera, pilihan, kesukaan, dan kebutuhan kita. Konsumsi mengambil nilai dari dan dalam konsumsi itu sendiri. Mengonsumsi menjadi sangat penting, bukan apa yang kita konsumsi atau apa yang sebenarnya kita inginkan. Oleh sebab itu, nilainilai dan perilaku sebagian orang dibatasi "realitas" yang disimulasikan dalam media. Kita mengira bahwa kebutuhan pribadi kita terpenuhi, tetapi kebutuhan ini sebenarnya adalah kebutuhan yang disamakan yang dibentuk oleh penggunaan tanda-tanda dalam media. (Littlejohn, Stephen W dan Foss, 2018)

Pada umumnya budaya massa dipengaruhi oleh budaya populer. Pemikiran tentang budaya pouler menurut Ben Agger dapat dikelompokkan pada empat aliran (Bungin, 2017)

(a) Budaya dibangun berdasarkan kesenangan namun tidak substansial dab mengentaskan orang dari kejenuhan kerja sepanjang hari

(b) Kebudayaan populer menghancurkan nilai budaya tradisional

(c) Kebudayaan menjadi masalah besar dalam pandangan ekonomi Marx kapitaslis, dan

(d) Kebudayaan populer merupakan budaya yang menetas dari atas.

Kebudayaan populer banyak berkaitan dengan masalah keseharian yang dapat dinikmati oleh semua orang atau kalangan orang tertentu, seperti pementasan mega bintang, kendaraan pribadi, fashion, model rumah, perawatan tubuh, dan semacamnya . (Bungin, 2017)

Kebudayaan post modern adalah sebuah dunia simulasi, yaitu dunia yang terbangun dengan pengaturan tanda, citra, dan fakta melalui produksi maupun reproduksi secara timpang tindih.

Kita telah melihat bahwa pengaruh teknologi media sterhadap masyarakat merupakan ide utama dibalik teori ekologi media. (Wes, Richard dan Turner, 2017)

1. Media memengaruhi hampir semua aspek dalam tindak tanduk masyarakat.

2. Media memengaruhi presepsi kita dan mengorganisasikan pengalaman-pengalaman kita.

3. Media mempersatukan seluruh dunia.

Dalam asumsi yang pertama, ditekankan bahwa kita tidak dapat menghindari pengaruh media dalam kehidupan. (Wes, Richard dan Turner, 2017) 
Dalam era Simulasi segala sesuatu hancur menjadi sesuatu yang lain. Segala sesuatu meledak ke sesuatu yang lain. Impuls atau peledakan adalah penyusutan ke dalam masing - masing yang lain, peringkasan yang luar biasa, penghancuran dua aras tradisional ke dalam aras lain. (Gora \& Olifia, 2019)

Zaman kode telah menggantikan zaman tanda. Hubungan antara kode dengan reproduksi reproduksi yang asli. Pada "kode" mensyaratkan bahwa objek yang dihasilkan sebagaimana jaringan pada bologi bukan seperti salinan sebagaimana bisa dipahami, di mana salian sebagai reproduksi dari objek yang asli. Perbedaan antara salinan dengan yang asli justru menjadi berlebihan. Realitas semu komunikasi global, hologram, dan seni adalah wilayah yang menunjukkan bentuk simulacra.(Gora \& Olifia, 2019)

Menurut Goulet Realitas masyarakat adalah masyarakat dengan sistem teknologi, yang baik atau masyarakat teknologi. Untuk mencapai masyarakat teknologi, maka suatu masyarakat harus memiliki sistem teknologi yang baik. (Bungin, 2017) 


\section{CONTOH KASUS}

\section{KASUS KOSMETIK ILEGAL YANG DI PROMOSIKAN ARTIS ENDORSE}

Badan Pengawas Obat dan Makanan (BPOM) RI mengimbau kepada seluruh artis yang menerima jasa "Endorse" produk harus selektif. Terutama mengecek terkait izin edar maupun lisensi keamanan. Dalam artiaan pastikan produk yang di endorse, pertama secara etika harusnya yang artis endorse mengkonsumsi juga. Jadi konsumen yang cerdas harus selalu memeriksa produk tersebut apakah sudah mendapat izin edar. Imbauan dari BPOM tersebut berkaca pada kasus dugaan terlibatnya enam artis "endorse" produk kosmetik ilegal beromzet ratusan juta per bulan di Surabaya beberapa pekan lalu. Polda Jatim merilis enam nama artis yang terlibat menjadi endorse produk kosmetik ilegal yakni VV, NR, MP, NK, DJB, dan DK. Menurutnya , para publik figur Endorse jangan hanya tergiur oleh nominal uang yang akan diterima, namun harus menjadi pengawas dalam meminimalisir peredaran produk berbahaya. Saat menerima permintaan Endorse suatu produk yang belum terkenal secara luas, para artis harus ikut kritis seperti mengecek izin edar, kandungan yang ada dalam suatu produk, nomor registrasi di BPOM, maupun penjualnya. Artis endorse harusnya selalu memeriksa produk yang diendorse itu. Tidak hanya memberikan iklan-iklan atau janji-janji kualitas, tapi yakin dulu (produk terdaftar di BPOM). 


\section{$\underline{\text { Kesimpulan }}$}

Tanda pada media promosi iklan memiliki keterkaitan visual dengan nuansa remaja dan juga untuk mengajak khalayak sebagai bagian dari konsumen dengan meyakinakan kesadaran khalayak bahwa kualitas produk terlihat nyata dan bisa ditirukan penggunaan gaya dan juga meyakinkan dari kualitas produknya. Adapun tanda dan simulasi iklan mencoba untuk menanamkan kesadaran palsu kepada masyarakat tentang ouput dari kualitas produk adalah nyata dan diyakini memiliki kualitas lebih. Makna tanda secara keseluruhan terlihat menitik beratkan pada warna, visual dan juga teks. Media berhasil membuat realitas baru yang salu mengedepankan hal yang sempurna untuk membuai manusia. Sebagai contoh adalah masalah tentang "relatif kecantikan". Media sangat realitas tentang kecantikan, bahwa kecantikan itu adalah wanita yang mempunyai kulit putih, hidung mancung, alis rapih, bulu mata cetar. Sehingga setiap wanita yang ingin tampil cantik harus memenuhi kreteria tersebut. Dan hal ini pun terjadi pada diri lelaki tersebut dimana media berhasil menciptakan realitas dimana lelaki tersebut akan mendapatkan perempuan yang ia inginkan yang tidak ia dapatkan di dunia nyata sesungguhnya. Oleh karena itu, media berhasil menciptakan tanda-tanda sebagai realitas yang baru yang lebih baik dari realitas yang sesungguhnya. Kita sebagai pengguna media sosial juga tidak sadar bahwa kebudayaan kita lama kelamaan akan terkikis oleh kebudayaan baru atau budaya populer. Dari kebiasaan kita memakai barang fashion dari luar negri, membeli barang dari luar negri, mendengarkan musik kpop, menonton film drama korea. Ketika kita melakukan semua hal itu memang secara tidak sadar kita lupa akan kebudayaan kita sendiri. Pemodelan endorse instagram disini terlihat bahwa figur model yang tidak dikenal dimanfaatkan sebagai objek atau alat komoditi bagi vendor iklan atau produsen dalam memasarkan produk. Dengan menekan biaya budgeting iklan atau media promosi yang berlebihan dengan menitikberatkan pada pembiayaan model, para vendor pun terlihat lebih menekan budget pada penggunaan model dengan memanfaatkan endorse remaja yang dapat dibayar lebih murah atau hanya bermodalkan penawaran eksistensi agar lebih dikenal sehingga menguntungkan bagi pihak produsen itu sendiri. 


\section{REFRENSI}

Bungin, M. B. (2017). Sosiologi Komunikasi (M. B. Bungin (ed.); 9th ed.). Kecana.

Gora, R., \& Olifia, S. (2019). Komodifikasi Model Endorse Dalam. Komodifikasi Model Endorse Dalam Industri Budaya Fashion Dan Kosmetika (HIperrealitas Fashion Endorse Pada Produk Kosmetik Dan Busana Remaja Di Media Sosial Instagram). https://osf.io/preprints/inarxiv/c3yd4/

Littlejohn, Stephen W dan Foss, K. A. (2018). Teori Komunikasi (R. Oktafiani (ed.); 9th ed.). Salemba Humanika.

Wes, Richard dan Turner, L. H. (2017). Pengantar Teori Komunikasi Analisis dan Aplikasi (D. E. Irawan (ed.); 5th ed.). Salemba Humanika. 